\title{
Black Cotton Soil in Highway Construction
}

\author{
${ }^{\text {"1 } P . ~ G u r u ~ R a j u, ~}{ }^{2}$ Hemant Kumar, ${ }^{3}$ Amit K. Verma \\ ${ }^{1}$ Afcons Infrastructure Limited, Mumbai, Maharashtra, 400053, India \\ ${ }^{2}$ Department of Mining Engineering, IIT(ISM) Dhanbad, Jharkhand, 826004 \\ ${ }^{3}$ Department of Mining Engineering, IIT(BHU), Varanasi, UP, 221005 \\ Email: gururaju.pokkunuri@afcons.com,hemant@iitism.ac.in,amitvermaism@gmail.com
}

Received: 06th November 2019, Accepted: 10th February 2020, Published: 29th February 2020

\begin{abstract}
The use of naturally available unsuitable soils in the construction of roads will open new avenues in the construction industry. The process of making the naturally available unsuitable soil being suitable is known as soil stabilisation. Black cotton (BC) soil is highly expansive in nature when gets in contact with water, thus making it unsuitable for construction. The unsuitability of $\mathrm{BC}$ soil can be changed by making the soil water repellent and exhibiting high bond strength. This can be achieved by application of Terrasil and Zycobond (A Zydex product) when added to soil mixed with water. It improves the bond strength between the soil particles and creates a protective layer by permanently changing the soil properties. It increases the California Bearing ratio of the soil mass exponentially over a period of time thus, making it suitable for infrastructure projects and high chances to be used as non-expansive $\mathrm{BC}$ soil in infrastructure development. This paper demonstrates the use of organosilane based nano materials and nano acrylic co-polymer to convert expansive $\mathrm{BC}$ soil into nonexpansive $\mathrm{BC}$ soil by stabilisation. This will have substantial impact on the use of naturally available unsuitable material which can be made suitable by stabilisation process.
\end{abstract}

\section{Keywords}

Organosilane Nano Material, Nano Acrylic Copolymer, Black Cotton Soil, Stabilisation, CBR

\section{Introduction}

It is a well-known fact that water is the worst enemy of all structures, particularly in expansive soil condition. Water penetrates into the foundation from three directions- top surface, side faces and from bottom layers due to capillary action. Therefore, specifications in expansive soil areas must take these factors into consideration. The surfacing must be impervious, sides paved and soil beneath well treated to check capillary rise of water. It has been found during handling of various investigation project assignments, for assessing causes of structural failures that water has got easy access into the foundations. It saturates the soil and thus lowers its bearing capacity, ultimately resulting in heavy depressions and settlement. Water lubricates the soil particles and makes the mechanical interlock unstable. In the top surface, ravelling, stripping and cracking develop due to water stagnation and its seepage into the bottom layers. Therefore, securing the soil beneath from ingress of water is a challenge and need of the hour to improve the durability of structures.

The structures on Black cotton soil (BC soil) bases develop undulations at the road surface due to loss of strength of the sub-grade through softening during monsoon. The physical properties of $\mathrm{BC}$ soil vary from place to place, $40 \%$ to $60 \%$ of the $\mathrm{BC}$ soil has particle size less than $0.001 \mathrm{~mm}$. At the liquid limit, the volume change is of the order of $200 \%$ to $300 \%$ and results in swelling pressure as high as $8 \mathrm{~kg} / \mathrm{cm}^{2}$ to $10 \mathrm{~kg} / \mathrm{cm}^{2}[1]$. laboratory soaked CBR values of Black Cotton soils are generally found in the range of 2 to $4 \%$ [1]. Due to very low CBR values of $\mathrm{BC}$ soil excessive pavement thickness is required for designing flexible pavement. Research \& Development (R\&D) efforts have been made to improve the strength characteristics of $\mathrm{BC}$ soil with new technologies.

Ahmed (2014) did experiments on soil stabilization using fly ash; it is an industrial by-product of coke combustion. The analysis involves physical and chemical properties of the soil. It has been shown that index properties of the clay have been improved. Increase in the bearing capacity of the soil was observed with varying fly ash ratios[2].Liquid limit and Plasticity index of soil decreases from $67.49 \%$ to $52.01 \%$ and $37.16 \%$ to $10.43 \%$ with increase in lime content up to $8 \%$. After that there is no significant change with increase in lime content [3].

The study on unsuitable soil using fly ash was done by researchers. The tests carried out with different percentage of fly ash indicated that the workability is maximum with $25 \%$ fly ash. Also, the dry density observed is maximum for $25 \%$ fly ash [4]. There was a considerable change in the CBR value of the treated soil. CBR changes were significant at $0.4 \%$ of SoilTech MK III polymer after 4 days of soaking as it achieves the required strength recommended by IRC: $37-2001$. CBR increases from $2.47 \%$ to $9.98 \%$ for unsoaked condition and from $1.58 \%$ to $7.48 \%$ for soaked condition at $0.4 \%$ of SoilTech MK III. This shows that there is an increase in the strength of the soil when stabilized with SoilTech MK III polymer [5]. Maximum values of CBR and UCS were obtained at $5 \%$ of SoilTech MKIII replaced to the OMC of the soil. With increase in soaking period 
of soil, the values of CBR and UCS results were reduced because of increase in moisture content in specimen. The UCS and CBR values of soil treated with SoilTech MKIII polymer increased compared to untreated soil [6].

Due to the presence of montmorillonite, which is characterized by large volume change from wet to dry seasons and vice versa, black cotton soil also facilitates compaction for obtaining the desired density with comparatively less effort. The properties of the black cotton soil may be altered in many ways viz, mechanical, thermal, chemical and other means of stabilization, it is very important to investigate the physical and engineering properties associated with the black cotton soil. Various methods are available to stabilize the soil and the method should be analysed in the laboratory initially with soil material before applying it on the field conditions [7]. But once matured the Terrasil and Zycobond combination in soil will not reduce the CBR of the stabilized soil even in soaked condition.

\section{Methodology}

The black cotton soil is very hard when it is dry but loses its strength completely in wet condition. The two components Terrasil and Zycobond were used as soil modifier to improve the BC soil properties even in wet condition.

Zycobond is nano acrylic co-polymer dispersion for the soil particles and imparting resistance to soil erosion and dust control. It is blended with organo-silane and showered on compacted soils. It enhances the quality of soil layer, controls soil disintegration, quick drying of soil layers after downpours and thus it helps in reducing maintenance cost.

Terrasil is organo-silane based nanomaterials soluble in water, easy to apply, UV \& heat stable reactive soil modifier to stabilize and waterproof soil. It reacts with water loving silanol groups of sand, silt, clay, and aggregates to convert it to highly stable water repellent alkyl siloxane bonds and forms a breathable in-situ membrane. It resolves the critical sub-surface issues. The untreated soil surface silicate structure and treated soil creating a molecular level hydrophobic membrane is shown in Figure 1.

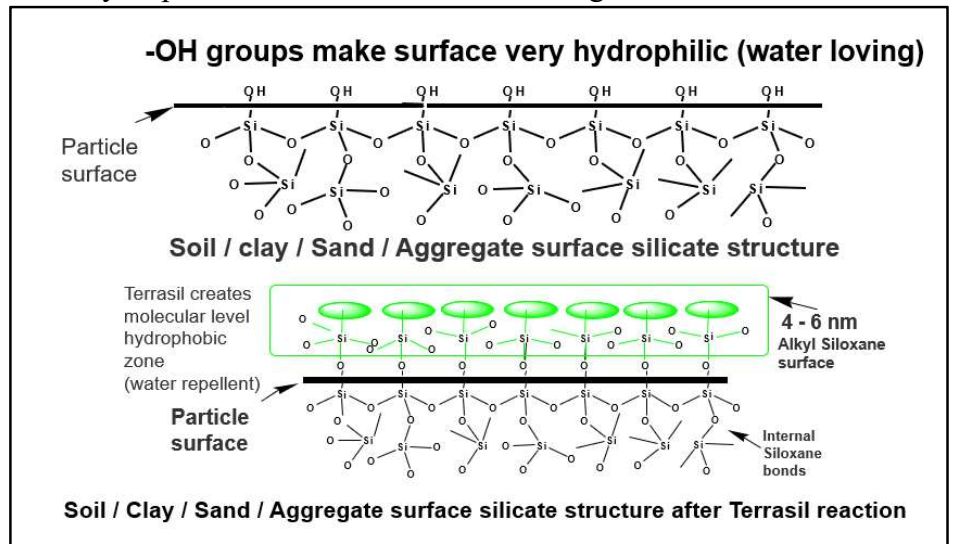

Figure 1: Reaction of Organo-Silane with Soil Particles

A standard method is required to follow during the stabilisation of BC soil using Organo-Silane (Terrasil) and Nano acrylic copolymer (Zycobond) in combination with lime at a designed dosage depending on the CBR requirement. Removal of top vegetation by clearing, grubbing and loosening the remaining soil for the required depth using grader or tractor with ripper arrangement is shown in Figure 2.

After ripping the soil rotavator is used with tractor to break the soil mass into small particles. The mixing of the soil with lime or cement shall be uniform using the ripper and the rotavator till no big lumps of soil is visible as shown in Figure 2Figure 2. The smaller the particle size preferably $10 \mathrm{~mm}$ down, better will be the treatment and performance of the treated soil.

The polymer shall be mixed with water in the tanker and spread over the entire stretch uniformly by consuming the required quantity. After each stage of spray, the soil needs to be mixed homogenously using ripper and rotavator to ensure the breaking and mixing of soil with polymer.

The mixed soil shall be left for drying so that the polymer gets absorbed in the soil mass and change its properties permanently. Generally, a drying time of one hour is kept to allow the polymer mixed water to be absorbed completely in the soil. The soil shall have moisture to complete the rolling. Rolling shall be done using the tandem roller of 10ton capacity for achieving the compaction as shown in Figure 4. 

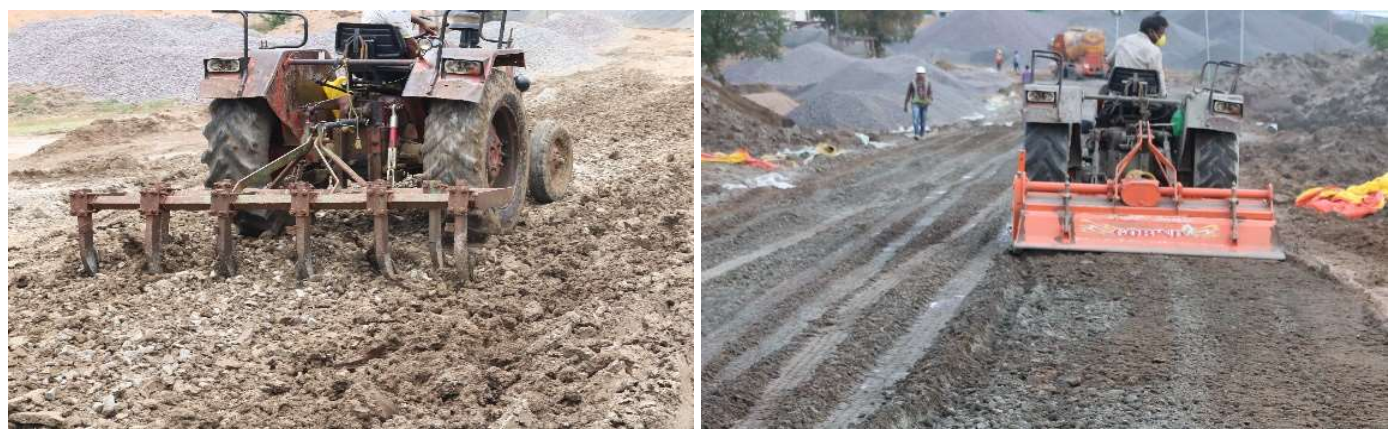

Figure 2: Alternate Use of Ripper and Rotavator for Breaking of Soil.
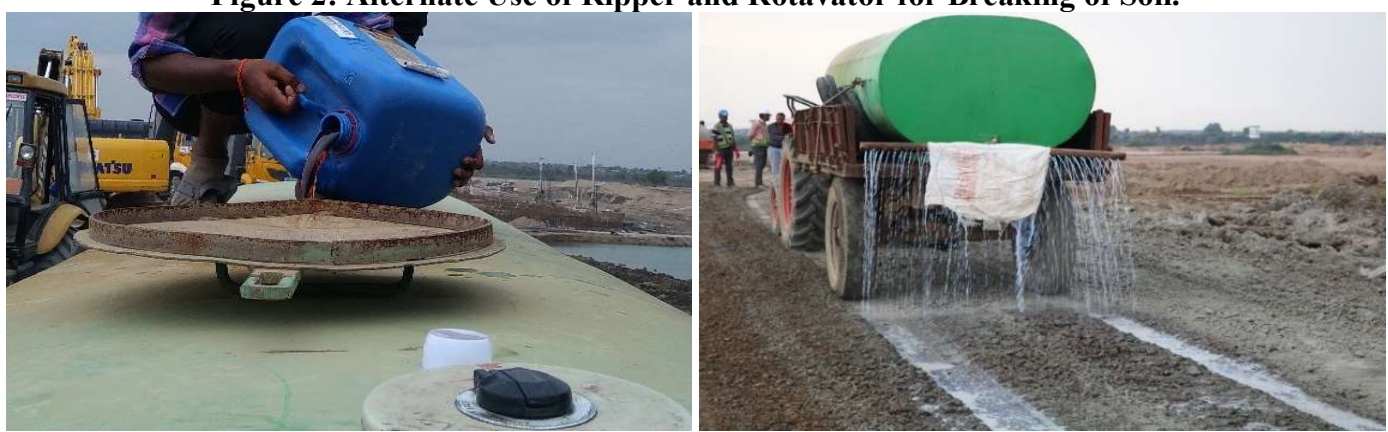

Figure 3: Mixing of Terrasil and Zycobond in Water and Spray on Field.

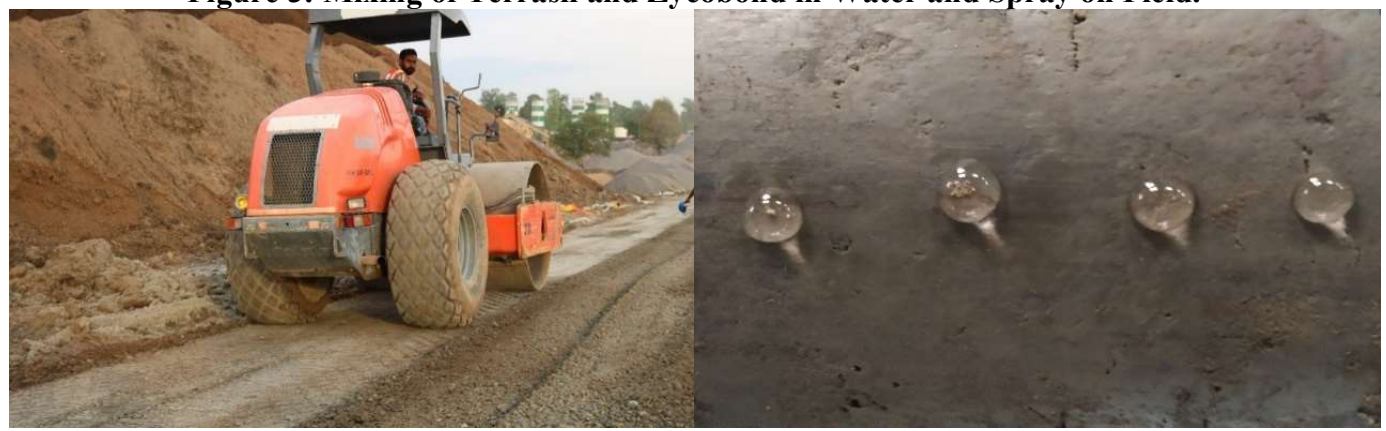

Figure 4: Compaction of Layer using 10 Ton Roller and Water Repellence on Treated Soil.

Check for water repellence as shown in Figure 4 after drying to ensure that the polymer is active. Allow traffic only after completing the curing time of four days, so that the bond between the polymer and soil matures completely.

\section{Results and Discussion}

The samples of BC soils having free swell index value $70 \%$ were used to check the change in properties using the stabilisation. The soil stabilisation is being done with and without addition of lime in the $\mathrm{BC}$ soil. The following changes in properties were observed during the test under different combination of Organosilane and nano acrylic copolymers with lime.

Free swell index of the soil helps to find out the potential of the soil to swell which is needed for further detailed investigation of swelling characteristics of soil under different field conditions. The test is carried out with reference to IS: 2720 (Part 40). It was observed that for BC soil with initial FSI of 70\% showed significant drop in the swelling value after stabilisation as shown in Table 1.

The CBR test is carried out as per IS: 2720 (Part-16) on different soil samples keeping the dosages of the additives same. Two sets of readings were observed during the test. One set showing the CBR of untreated soil and the other showing the CBR of treated soil with lime and organosilane nanomaterials. The CBR samples were prepared at their corresponding maximum dry density and OMC. For each test three similar samples were prepared. The CBR sample which are prepared with Lime, Terrasil and Zycobond are kept under the halogen light at $40^{\circ} \mathrm{C}$ inside the building (or under the sun light) for four days. After that, the CBR samples were immersed into the water for 4 Days soaking for testing. The result of the same are presented in Table 1 and the variation in CBR values of treated soil is shown in Figure 3. The controlled CBR of BC soil having FSI value $70 \%$ is $1.86 \%$ when tested as per IS 2720 part- 16 . The CBR values increases by 1.2 times, Free swell index is reduced by $20 \%$, maximum dry density when tested as per IS 2720 part 8 is increased by $4.83 \%$ and optimum 
moisture content is reduced by $32.1 \%$ when treated with organosilane and nano acrylic copolymer alone at dosage of one kg per cum each.

With addition of two percent lime and varying the dosages of organosilane and nano acrylic copolymer from 0.5 to $1 \mathrm{~kg}$ per cum the CBR values increases by five times, Free swell index is reduced by $60 \%$, maximum dry density when tested as per IS 2720 part 8 is increased by $7.25 \%$ and optimum moisture content is reduced by $34.30 \%$. Upon increasing the lime content from 2 to 3 percent without changing the additives percentage, the CBR value increased by ten times as shown in Table 1 .

\begin{tabular}{|c|c|c|c|c|c|c|c|}
\hline \multirow{2}{*}{ Particulars } & Terrasil & Zycobond & Lime & FSI & MDD & OMC & CBR \\
\hline & $\mathbf{k g} / \mathrm{m}^{3}$ & $\mathrm{~kg} / \mathrm{m}^{3}$ & $\%$ & $\%$ & Gm/cc & $\%$ & $\%$ \\
\hline \multirow{9}{*}{ 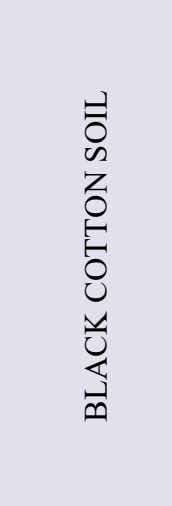 } & 0.0 & 0.0 & 0.0 & 70 & 1.820 & 13.7 & 1.86 \\
\hline & 0.5 & 1.0 & 0.0 & 60 & 1.877 & 11.4 & 1.84 \\
\hline & 0.8 & 1.0 & 0.0 & 55 & 1.891 & 9.9 & 2.11 \\
\hline & 1.0 & 1.0 & 0.0 & 50 & 1.908 & 9.3 & 2.20 \\
\hline & 0.5 & 0.5 & 2.0 & 55 & 1.873 & 12.0 & 8.20 \\
\hline & 0.7 & 0.7 & 2.0 & 40 & 1.888 & 10.2 & 9.72 \\
\hline & 1.0 & 1.0 & 2.0 & 20 & 1.952 & 9.0 & 10.20 \\
\hline & 0.5 & 0.5 & 3.0 & 40 & 1.886 & 12.8 & 13.72 \\
\hline & 1.0 & 1.0 & 3.0 & 15 & 1.961 & 9.2 & 18.30 \\
\hline
\end{tabular}

Table 1: Change in Properties of BC Soil after Stabilisation

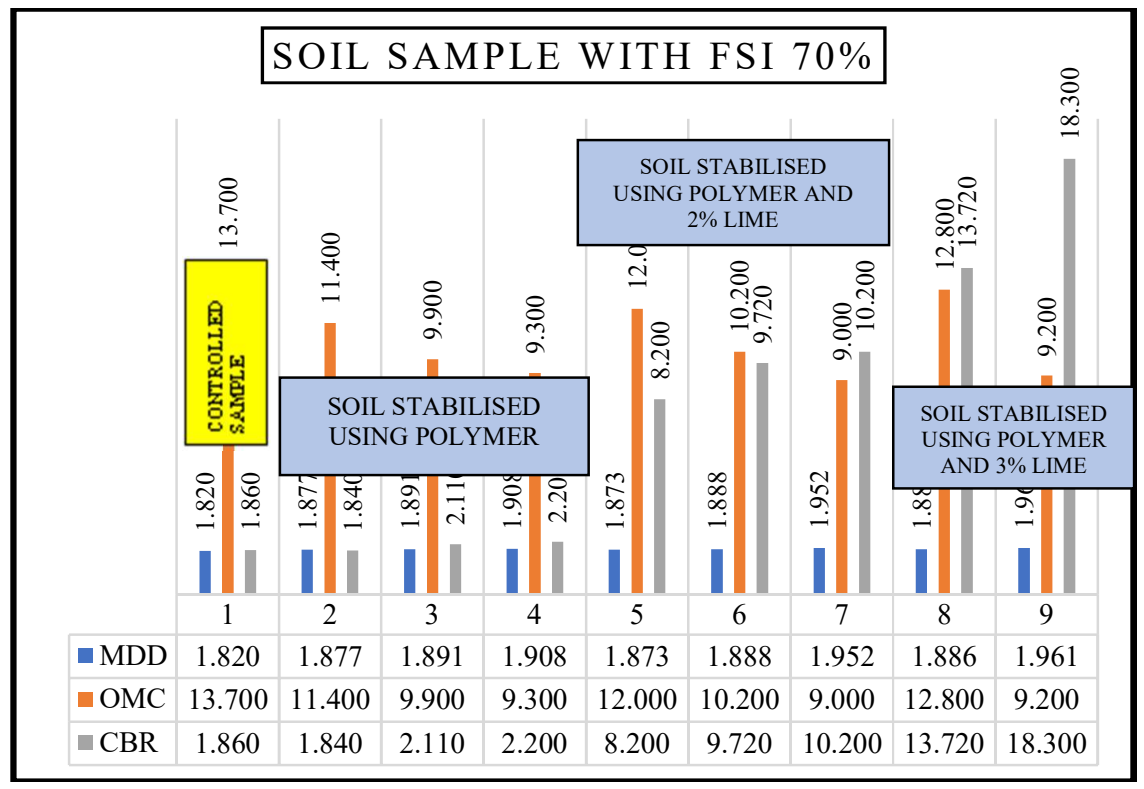

Figure 5: Change in Index Properties of High Plasticity Soil

\section{Conclusion}

The construction of foundation for structure on black cotton soils is a challenge to civil engineers. The reduction in the swelling properties of the BC soil will change the industry demand dramatically. This will improve the construction time and protect the environment. The use of Terrasil and Zycobond alone is not sufficient to raise the CBR significantly for highly compressible soil. The addition of lime by $2 \%$ has increased the CBR five times whereas $3 \%$ lime addition has changed the CBR by nine times. Since the Indian roads are designed for a subgrade of CBR $10 \%$ to $12 \%$ it won't be difficult to achieve the same even with existing highly compressible Black Cotton soil. This will eliminate the need to search for suitable borrow area and compliance of the legal requirements in order to mine the suitable soil for the project. This will save the natural resources and without disturbing the balance the projects can be completed with less pain and money. 


\section{Acknowledgement}

The authors would like to acknowledge the Zydex Team lead by Mr Rajesh Pitroda for their support in completing this research. Special thanks to Mr Himanshu Agrawa-l Head, Roads Division, for his guidance and support in conducting trials at project to judge the performance of the product. Finally we are thankful to the entire team of Afcons Infrastructure Limited and Mr Giridhar Rajgopalan, Executive Director (Technical) as without his vision these tests would not have been possible.

\section{References}

1. Bhuvaneshwari, S., et al. "Stabilization of Expansive Soils Using Flyash." Fly Ash India, no. 1, 2005, pp. $1-10$.

2. Ghais, Afaf Abadi ahmad. Fly Ash Utilization in Soil Stabilization. no. May 2014, 2014, doi:10.15242/iicbe.c514601.

3. Giridhar, V., et al. Behaviour of Black Cotton Soil Using Soiltech MKIII Polymer as a Stabilizer. 2017, pp. 2613-18, doi:10.15680/IJIRSET.2017.0602092.

4. Kumar, J. Ranjitha; D. K. Supritha; P. Hitaishi; Pratik. "Experimental Study on Black Cotton Soil Stabilized Using Soiltech Mk Iii Polymer." International Journal of Research in Engineering and Technology, vol. 05, no. 16, 2016, pp. 30-34, doi:10.15623/ijret.2016.0516007.

5. Shreyas, K. "'Stabilization of Black Cotton Soil Using Admixtures."” International Journal of Advance Engineering and Research Development, vol. 3, no. 05, 2016, doi:10.21090/ijaerd.030574.

6. Shweta Kandpal, Amit Pandey, Harshvardhan Ingawale. "Study of Stabilization of Black Cotton Soil." Ijered, vol. 5, no. 6, 2017, pp. 939-42.

7. YADAV, R. K., and ANKIT JAIN. "Effect of Chemicals on Index Properties of Soil." International Research Journal of Engineering and Technology, vol. 3, no. 11, 2016, pp. 749-52. 